\title{
A large scale expression study associates uc.283-plus IncRNA with pluripotent stem cells and human glioma
}

\author{
Marco Galasso', Paola Dama', Maurizio Previati', Sukhinder Sandhu², Jeff Palatini', Vincenzo Coppola ${ }^{2}$, \\ Sarah Warner ${ }^{2}$, Maria E Sana ${ }^{1}$, Riccardo Zanella ${ }^{1}$, Ramzey Abujarour ${ }^{5}$, Caroline Desponts ${ }^{6}$, Michael A Teitell ${ }^{7}$, \\ Ramiro Garzon², George Calin ${ }^{4}$, Carlo M Croce ${ }^{2}$ and Stefano Volinia ${ }^{1,2,3^{*}}$
}

\begin{abstract}
Background: There are 481 ultra-conserved regions (UCRs) longer than 200 bases in the genomes of human, mouse and rat. These DNA sequences are absolutely conserved and show 100\% identity with no insertions or deletions. About half of these UCRs are reported as transcribed and many correspond to long non-coding RNAs (IncRNAs).
\end{abstract}

Methods: We used custom microarrays with 962 probes representing sense and antisense sequences for the 481 UCRs to examine their expression across 374 normal samples from 46 different tissues and 510 samples representing 10 different types of cancer. The expression in embryonic stem cells of selected UCRs was validated by real time PCR.

Results: We identified tissue selective UCRs and studied UCRs in embryonic and induced pluripotent stem cells. Among the normal tissues, the uc.283 IncRNA was highly specific for pluripotent stem cells. Intriguingly, the uc.283-plus IncRNA was highly expressed in some solid cancers, particularly in one of the most untreatable types, glioma.

Conclusion: Our results suggest that uc.283-plus IncRNA might have a role in pluripotency of stem cells and in the biology of glioma.

\section{Background}

Long non-coding RNAs (lncRNAs) are involved in many biological processes [1]. Transcribed ultra-conserved regions (T-UCRs) are a large portion of the so-called ultraconserved regions (UCRs). The 'ultra-conserved' term was originally proposed for genomic regions longer than $200 \mathrm{bp}$ that are absolutely conserved $(100 \%$ homology with no insertions or deletions) in human, mouse, and rat genomes [2]. Many of these elements possess tissuespecific enhancer activity [3-5] and others have been shown to associate with splicing regulators. Evolutionary conservation has become a powerful tool to identify

\footnotetext{
* Correspondence: s.volinia@unife.it

${ }^{1}$ Biosystems Analysis, LTTA, Department of Morphology, Surgery and Experimental Medicine, Università degli Studi, Via Fossato di Mortara, 70, Ferrara 44123, Italy

${ }^{2}$ Comprehensive Cancer Center, Wexner Medical Center, and Biomedical Informatics, Ohio State University, Columbus, OH 43210, USA

Full list of author information is available at the end of the article
}

functionally important regions in the human genome [6]. A high proportion of UCRs show extreme conservation within mammals only and nearly $47 \%$ of UCRs in human have been localized to exons of genes involved in RNA processing or in the regulation of transcription and development $[2,7]$. The reasons for this extreme conservation remain a mystery, but it was proposed that UCRs play a role in the ontogeny and phylogeny of mammals and other vertebrates. This idea is supported by the identification of a distal enhancer and an ultra-conserved exon derived from a retroposon active more than 400 million years ago in lobe-finned fishes and terrestrial vertebrates, and maintained as active in the 'living fossil' coelacanth [2]. Another study showed the concurrent presence of enhancer and transcript functions in nonexonic UCRs, and suggested that they may belong to non-coding RNAs (ncRNAs) [8]. Recently, a positive correlation of expression with conservation and epigenetic 
marks was described in T-UCRs, among other ncRNAs [9]. Despite still having largely unknown roles, T-UCRs are thus now thought to act as 'regulators' of other RNAs [10].

Recent studies suggested that UCRs could contribute to the development of malignancies [11,12]. Genomewide profiling revealed that UCRs have distinct signatures in human leukemias and carcinomas [13] and are frequently located at fragile sites and in cancer-associated genomic regions [14]. Clinical findings also suggested that UCR signatures can have independent prognostic value in high-risk neuroblastoma patients [15] by providing additional prognostic value in conjunction with $N-M Y C$ activity/amplification [16]. Additionally, SNPs within UCRs were associated with increased familial breast cancer risk [17].

We performed this large scale study to identify UCR activity in cancer, analyzing almost 900 human samples from a panel of 46 normal tissues and 10 solid cancers using a custom-made microarray platform.

\section{Methods \\ UCR expression arrays}

We studied the expression of UCRs using the Ohio State University Comprehensive Cancer Center (OSUCCC) custom microarray [18]. The Gene Expression Omnibus describes the OSU-CCC 4.0 platform under accession number GPL14184. Briefly, a sense and an anti-sense 40-mer probe were designed for each of 481 UCRs. Each probe was printed in duplicate in two different slide locations, and therefore quadruplicate measures were available. Total RNA $(2 \mu \mathrm{g})$ were used for labeling and hybridization. The microarrays were hybridized in $6 \mathrm{X}$ SSPE $\left(0.9 \mathrm{M} \mathrm{NaCl} / 60 \mathrm{mM} \mathrm{NaH} \mathrm{PO}_{4} \cdot \mathrm{H}_{2} \mathrm{O} / 8 \mathrm{mM}\right.$ EDTA, $\mathrm{pH} 7.4) / 30 \%$ formamide at $25^{\circ} \mathrm{C}$ for $18 \mathrm{~h}$, washed in $0.75 \mathrm{X}$ TNT (Tris $\mathrm{HCl} / \mathrm{NaCl} /$ Tween 20 ) at $37^{\circ} \mathrm{C}$ for 40 minutes. Processed slides were scanned using a microarray scanner (Axon Molecular Devices, Sunnyvale, CA, USA), with the laser set to $635 \mathrm{~nm}$, at a fixed PMT (photomultiplier tube) setting, and a scan resolution of $10 \mathrm{~mm}$. Microarray images were analyzed using GenePix Pro and postprocessing was performed essentially as described earlier [18].

\section{Data analysis}

T-UCRs were retained when present in at least $20 \%$ of samples and when at least $20 \%$ of them had a fold change of more than 1.5 from the gene median. Absent calls were thresholded prior to normalization and statistical analysis. Normalization was performed by using quantiles [19]. First, all samples were classified according to organ, tissue and cell type; the samples were then grouped in systems (Additional file 1) and cancer types (Additional file 2). To assess the specificity of UCR expression across groups we used information content (IC) [20]. Differentially expressed RNAs were identified using $t$-tests over two-class experiments or $F$-tests over multiple classes (that is, various normal tissues) within the class comparison tool [21].

\section{Computational methods and folding free energies}

Computational methods were used to investigate uc.283plus and predict secondary structure for its RNA sequence. To investigate secondary structure, we used the RNAfold web server in the freely available ViennaRNA package version 2.0 to compute the centroid secondary structure and the corresponding free energy changes for folding, the minimum free energy (MFE; $\mathrm{kcal} / \mathrm{mol}$ ). In order to detect putative microRNA (miRNA) target sites in the considered region, we used IntaRNA, freely available online [22,23]. Calculation of accessibility is based on ensemble free energies. Ensemble free energies were calculated using a partition function approach assuming global folding of the ncRNA and local folding of the mRNA. For this purpose, RNAfold and RNAup are integrated into IntaRNA via the ViennaRNA library [24]. Highly stable miRNA-target duplexes are represented as having a very low hybridization energy.

\section{RNA expression and validation}

Mouse embryonic stem cell (ESC) lines (V6.4; hybrid $129 / \mathrm{C} 57 \mathrm{Bl} / 6$ ) were cultured at $37^{\circ} \mathrm{C}$ in $5 \% \mathrm{CO}_{2}$ in specific medium and total RNA was extracted using TRIzol. RNA samples were treated with 1 U DNase I Ampl Grade (Invitrogen Life Technology, Carlsbad, CA, USA) to remove any contaminating genomic DNA.

Total RNA was reverse transcribed using random hexamers (Invitrogen Life Technologies, Carlsbad, CA, USA). T-UCR expression was quantified by quantitative PCR (qPCR) with SYBR green. All reactions were performed in triplicate and 18S rRNA was used as reference. The triplicate $\mathrm{Ct}$ values were averaged and normalized $\mathrm{Ct}(\Delta \mathrm{Ct})$ calculated. The living conditions of the mice were appropriate for their species and all mouse experiments were approved by the Institutional Animal Care and Use Committee (IACUC) and University Laboratory Animal Resources (ULAR) of The Ohio State University. The animals were euthanized as per the IACUC approved guidelines and protocols before harvesting the tissues. RNA purity was assessed by the ratio of absorbance at 260 and $280 \mathrm{~nm}$ (A260/280 nm) using a NanoDrop ND-1000 (NanoDrop Inc., Wilmington, DE, USA). All tissues were obtained under the guidelines of approved protocols from the Ohio State University Internal Review Board and informed consent was obtained from each subject. RNA profiles for the human tissue and cell line samples have been deposited at ArrayExpress (E-TABM-969 and ETABM-970) and at the NCBI Gene Expression Omnibus 
(GSE16654). Cancers samples were deposited at Array Express (E-TABM-971 for breast carcinoma, E-TABM46 for colorectal adenocarcinoma, E-TABM-22 for lung cancer, E-TABM-343 for ovarian carcinoma, and ETABM-49 for prostate adenocarcinoma), and at the Gene Expression Omnibus (GSE7828 for colorectal carcinoma, GSE20099 and GSE24839 for esophagus carcinoma, GSE53504 for glioma and GSE14936 for lung adenocarcinoma and squamous carcinoma).

\section{Results and discussion}

\section{T-UCR expression in normal human tissues}

We tested the expression of UCRs in 374 samples from 46 types of normal tissues, belonging to 16 histological groups [25]. For UCR profiling we used the OSUMC microarray platform, previously validated in two large scale studies $[18,26]$. This platform has probes for 481 putative T-UCRs in either genomic strand (designated 'plus' or 'minus'; in some other studies defined ' + ' or ' $+\mathrm{A}$ ', respectively). A global analysis showed that only a portion of the UCRs (296 out of 962) was expressed in human tissues ( $P$-value $<0.001$; Additional file 3 ); $48 \%$ of these were non-exonic, $26 \%$ putative exonic and $26 \%$ exonic, proportions that reflect previously published studies $[13,14]$. Fifty-seven T-UCRs were transcribed bidirectionally (Additional file 4). Tissue selectivity was calculated using the IC [20]. The most tissue-selective UCRs were represented by a group of 15 UCRs, mostly expressed in epidermis, with an IC value ranging from 3.23 to 1.70 (Figure 1; Additional file 5). These $15 \mathrm{~T}$ UCRs were not located in the same genomic cluster. Another tissue-specific RNA was uc.450-plus, which is highly expressed in the central nervous system. This finding confirms previous data showing that uc. 450 was expressed in the dorsal root ganglion and the neural tube [27]. In particular, Visel et al. [27] hypothesized an enhancer function for hs385, which fully includes uc.450. Interestingly, the opposite probe, uc.450-minus, was specific for the respiratory system. Uc.174-minus, located on the opposite strand of the MATR3 exon, was expressed mainly in the respiratory system and epidermis. The placenta was characterized by the expression of uc.319-minus

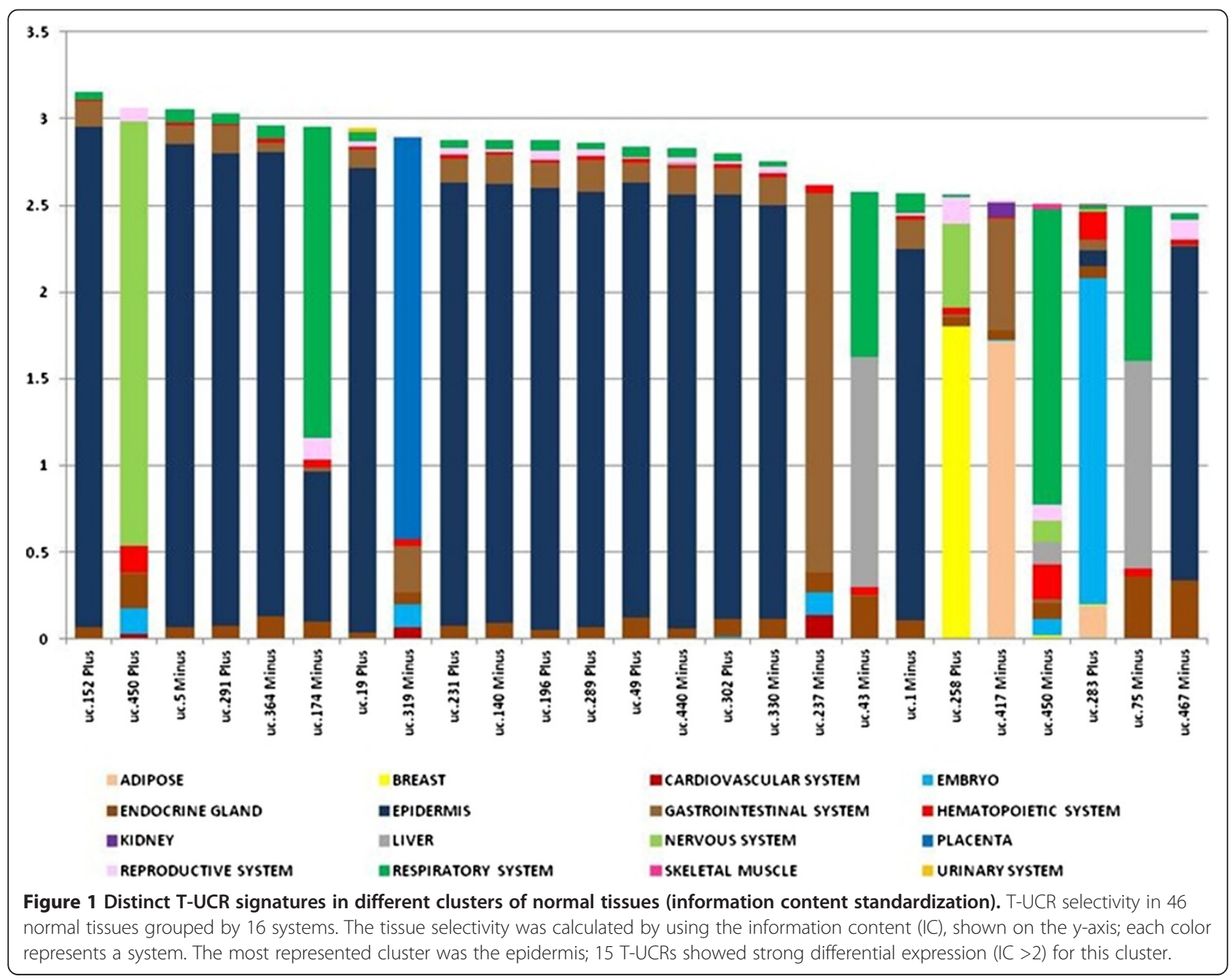


(intergenic), while uc.237-minus (intronic) was restricted to the gastrointestinal system. Uc.43-minus (intronic; our probe is homologous to Mus musculus CN668140 EST), uc.75-minus, located on the opposite strand of the last exon of $Z E B 2$, and uc.42-plus (intronic) were expressed in both liver and the respiratory system. In addition, uc.417-minus was expressed in adipose tissue and in the gastrointestinal system. The only UCR selective for embryo was uc.283-plus, on which we focus for the rest of this study.

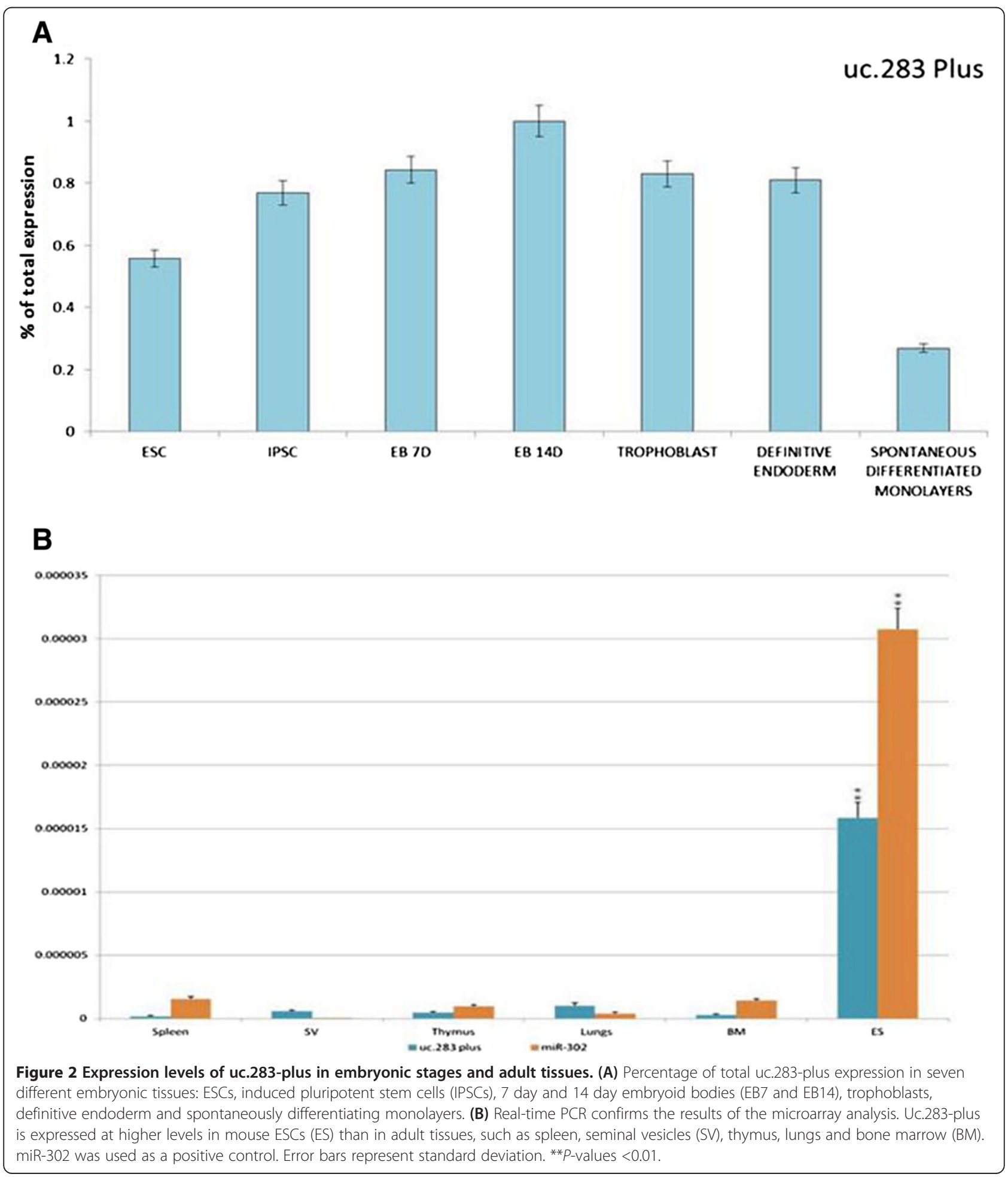




\section{A single T-UCR is differentially expressed in pluripotent stem cells}

Our extensive study of UCR tissue selectivity identified only one RNA specific for the embryo. To further investigate this finding we studied ESCs and induced pluripotent stem cells. Uc.283-plus, a 277 nucleotide-long sequence located at chr10:50,604,757-50,605,033, was sufficient to discriminate between adult tissues and pluripotent stem cells. Figure $2 \mathrm{~A}$ shows the expression of uc.283-plus at distinct stages of differentiation. Uc.283plus displayed high values in human ESCs and induced pluripotent stem cells, increased in trophoblasts at 7 and 14 days of embryoid body differentiation, and decreased in definitive endoderm to reach the lowest values in spontaneously differentiated monolayers.

To validate our microarray data that suggest uc.283plus is pluripotent specific, we used qPCR on RNAs extracted from the mouse ESCs and RNAs from five mouse adult tissues (spleen, seminal vesicles, thymus, lung, and bone marrow). We used ESC-specific miR-302 as a positive ncRNA control $[20,25]$. The qPCR (Figure 2B) confirmed strong and mouse ESC-selective expression for both
miR-302 and uc.283-plus (Wilcoxon test $P$-value $<0.01$ ) (Additional file 6). No enhancer activity was associated in Vista Enhancer Browser [5] with uc.283. In a further quest to investigate the possible function of uc.283, we analyzed a 2,000 bp region surrounding this UCR using the UCSC Genome Browser. In the H1-hESC chromatin state segmentation (HMM track from ENCODE/Broad), this sequence might be an inactive or poised promoter [28]. In addition, the edges of uc. 283 overlap with the initial tracts of two open chromatin regions (OpenChrom_15681 and OpenChrom_15682). Data from the methyl $450 \mathrm{~K}$ bead array track (ENCODE/HAIB) showed that, in close proximity to the start of uc.283-plus, the CpG sequence was not methylated in H1-hESC and human umbilical vein endothelial cells, and partially or totally methylated in other cell types. These findings, together with the proximity to open chromatin regions, suggested that uc.283-plus could be located in a euchromatic region during embryonic development and in ESCs. Furthermore, uc.283-plus is not present in the catalogue of lncRNAs originated from divergent transcription at promoters of active proteincoding genes [29]. In particular, there seems to be no

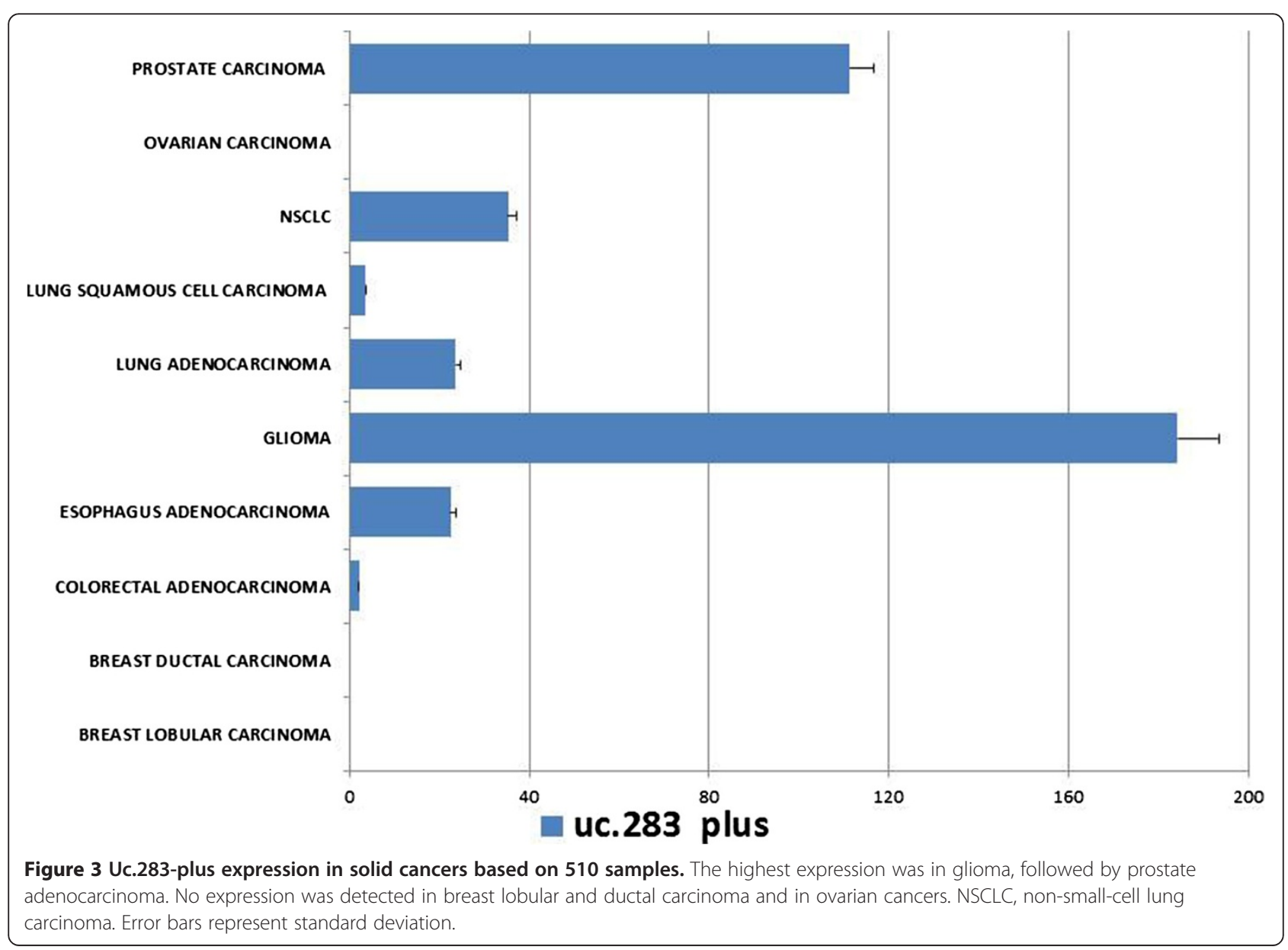


connection between uc.283-plus and the adjacent CpG island, containing the DRGX (Dorsal root ganglia homeobox) promoter (on the opposite strand).

\section{Among solid cancers uc.283-plus is mostly expressed in glioma}

Cancer stem cells are a highly debated issue in oncology [30,31]. Since uc.283 was associated with pluripotency, we assessed its RNA levels in about 500 tumors from several types of solid cancers. Surprisingly, uc.283-plus was over-expressed in prostate adenocarcinoma and glioma samples (Figure 3). Recently, lncRNAs were investigated in glioma to define grade and histological differentiation of the tumor [32]. The highest levels of expression were found in glioma, considered one of the most aggressive cancers with high propensity for proliferation and tissue invasion. It is tempting to speculate that the high expression of uc.283-plus in glioma is correlated with a 'cancer stem cell phenotype', a wellstudied event occurring in glioma [33]. Interestingly, Lujambio et al. [34] identified an RNA in the uc.283 genomic region but transcribed from the opposite strand in various types of cancer cell lines. They also showed that uc.283-minus undergoes specific CpG island hypermethylation, suggesting that it could be regulated by epigenetic alteration. Recently, Hudson et al. [35] confirmed the up-regulation of uc.283-minus in a prostate cancer cell line treated with the DNA hypomethylating agent 5-azacytidine and with the histone deacetylase inhibitor trichostatin A. Hudson et al. produced a list of all the possible ucRNA-mRNA interactions based on sequence complementarity according to the thermodynamics of the loop-loop RNA interactions [36,37]. In order to assess whether uc.283-plus has a functional role, we checked for possible interactions with the mRNAs listed but did not find any. Subsequently, we hypothesized that it has a 'sponge function' for recruitment of miRNAs or other class of ncRNAs. We examined the possible secondary structure of uc.283-plus (Figure S1A,B in Additional file 7) [24] and submitted the RNA sequence to the web-tool application RegRNA2.0 [38], analyzing predicted miRNA target sites with a score $\geq 150$ and a free energy of -20 or less. We found that our transcript sequence could be a target of three miRNAs: hsa-miR-4555p, has-miR-640 and has-miR-1909-3p. We verified these possible interactions using another algorithm, IntaRNA (Figure S1C in Additional file 7) [22]. Interestingly, hsamiR-1909-3p was discovered in human ESCs by deep sequencing of small RNA libraries [39] and targeted genes, such as DICER1, SOX2 and NOTCH1 [40]. Hsa-miR-455$5 \mathrm{p}$ and hsa-miR-640 were deregulated in several cancers but were not the most abundant isoforms and they have not been well characterized yet $[41,42]$. Very recently,
Liz et al. [10] showed that the long ncRNA uc.283-minus controlled pri-miRNA processing. This ncRNA-ncRNA interaction prevents pri-miRNA-195 cleavage by Drosha. Therefore, understanding the interactions of this kind of ncRNA is of particular importance to pinpoint their biological meaning.

\section{Conclusion}

We report here the genome-wide analysis of UCR tissue selectivity among 16 human histologic groups, corresponding to 46 different normal tissues. A fraction of UCRs were tissue-selective, while others were broadly expressed. Uc.283-plus was highly expressed in pluripotent ESCs and induced pluripotent stem cells. Uc.283-plus may play an important role in pluripotency and among solid cancers it is highly expressed in glioma. The understanding of the biological roles of UCRs, as those of the other lncRNAs, remains an open challenge. This study can be a starting point for the further characterization of UCR activities in normal and cancer tissues.

\section{Additional files}

\begin{abstract}
Additional file 1: Table S1. The number of microarray chip samples used is reported for each system type.

Additional file 2: Table S2. The number of microarray chip samples used is reported for each cancer type.

Additional file 3: Table S3. Class comparison analysis: expression levels of tissue-selective T-UCRs.

Additional file 4: Table S4. T-UCR that are bidirectional in normal cluster tissues.

Additional file 5: Table S5. Tissue specific T-UCRs in normal tissues. Sorted by information content (IC). The genomic coordinates came from hg19.

Additional file 6: Table S6. Expression levels are calculated as $2^{(-\Delta \Delta C T)}$ using $18 \mathrm{~S}$ rRNA as a reference. Average of at least three experiments, each PCR performed in triplicate. Standard errors (ERR.ST.) are reported.

Additional file 7: Figure S1. (A) The uc.283-plus folding structure for the minimum free energy prediction. The optimal secondary structure has a minimum free energy of $-65.70 \mathrm{kcal} / \mathrm{mol}$. (B) The centroid secondary structure with a minimum free energy of $-32.80 \mathrm{kcal} / \mathrm{mol}$. (C) Hsa-miR-640, hsa-miR-1909-3p and hsa-miR-455-4p target uc.283-plus in three different positions with different hybridization energy values.
\end{abstract}

\section{Abbreviations}

bp: base pair; ESC: embryonic stem cell; IC: information content; IncRNA: long non-coding RNA; miRNA: microRNA; ncRNA: non-coding RNA; qPCR: quantitative polymerase chain reaction; SNP: single-nucleotide polymorphism; T-UCR: transcribed ultra-conserved region; UCR: ultraconserved region.

\section{Competing interests}

The authors declare that they have no competing interests.

\section{Authors' contributions}

MG and SV designed the study and drafted the manuscript. JP and SW helped in acquisition of data. PD and SS carried out the RT-PCR. MG, MES and RZ helped with statistical analysis. MAT, GC, VC and CMC helped in analysis and interpretation of the data. RAJ, CD and RG helped to revise the manuscript. JP, MP and SV helped in writing the paper. All authors read and approved the final manuscript. 


\section{Acknowledgements}

Microarray analyses were performed using BRB-ArrayTools developed by Dr Richard Simon and the BRB-ArrayTools Development Team, GenePattern (Broad Institute), BioConductor and R.

\section{Funding}

SV was supported by AIRC (IG 13585), PRIN MIUR 2010 and CNR EPIGEN grants. MG was supported by Contributo UNIFE Fondi 5X1000 - ANNO 2011.

\section{Author details}

${ }^{1}$ Biosystems Analysis, LTTA, Department of Morphology, Surgery and Experimental Medicine, Università degli Studi, Via Fossato di Mortara, 70, Ferrara 44123, Italy. ${ }^{2}$ Comprehensive Cancer Center, Wexner Medical Center, and Biomedical Informatics, Ohio State University, Columbus, OH 43210, USA. ${ }^{3}$ Biomedical Informatics, Ohio State University, Columbus, OH 43210, USA ${ }^{4}$ Experimental Therapeutics \& Cancer Genetics, MD Anderson Cancer Center, Houston, TX 77030, USA. ${ }^{5}$ Fate Therapeutics, 3535 General Atomics Ct, San Diego, CA 92121, USA. ${ }^{6}$ Department of Chemistry, The Scripps Research Institute, 10550 North Torrey Pines Road, La Jolla, CA 92037, USA 7Department of Pathology \& Laboratory Medicine, David Geffen School of Medicine at UCLA, Los Angeles, CA 90095, USA

Received: 14 June 2014 Accepted: 16 September 2014

Published online: 02 October 2014

\section{References}

1. Mercer TR, Dinger ME, Mattick JS: Long non-coding RNAs: insights into functions. Nat Rev Genet 2009, 10:155-159.

2. Bejerano G, Pheasant M, Makunin I, Stephen S, Kent WJ, Mattick JS, Haussler D: Ultraconserved elements in the human genome. Science 2004, 304:1321-1325.

3. Bejerano G, Lowe CB, Ahituv N, King B, Siepel A, Salama SR, Rubin EM, Kent WJ, Haussler D: A distal enhancer and an ultraconserved exon are derived from a novel retroposon. Nature 2006, 441:87-90.

4. Poulin F, Nobrega MA, Plajzer-Frick I, Holt A, Afzal V, Rubin EM, Pennacchio $L A$ : In vivo characterization of a vertebrate ultraconserved enhancer. Genomics 2005, 85:774-781.

5. Pennacchio LA, Ahituv N, Moses AM, Prabhakar S, Nobrega MA, Shoukry M, Minovitsky S, Dubchak I, Holt A, Lewis KD, Plajzer-Frick I, Akiyama J, De Val S, Afzal V, Black BL, Couronne O, Eisen MB, Visel A, Rubin EM: In vivo enhancer analysis of human conserved non-coding sequences. Nature 2006, 444:499-502.

6. Baira E, Greshock J, Coukos G, Zhang L: Ultraconserved elements: genomics, function and disease. RNA Biol 2008, 5:132-134.

7. Katzman S, Kern AD, Bejerano G, Fewell G, Fulton L, Wilson RK, Salama SR, Haussler D: Human genome ultraconserved elements are ultraselected. Science 2007, 317:915.

8. Licastro D, Gennarino VA, Petrera F, Sanges R, Banfi S, Stupka E: Promiscuity of enhancer, coding and non-coding transcription functions in ultraconserved elements. BMC Genomics 2010, 11:151.

9. Nielsen MM, Tehler D, Vang S, Sudzina F, Hedegaard J, Nordentoft I, Orntoft TF, Lund AH, Pedersen JS: Identification of expressed and conserved human noncoding RNAs. RNA 2014, 20:236-251.

10. Liz J, Portela A, Soler M, Gomez A, Ling H, Michlewski G, Calin GA, Guil S, Esteller M: Regulation of pri-miRNA processing by a long noncoding RNA transcribed from an ultraconserved region. Mol Cell 2014, 55:3-4.

11. Fabbri M, Garzon R, Andreeff M, Kantarjian HM, Garcia-Manero G, Calin GA: MicroRNAs and noncoding RNAs in hematological malignancies: molecular, clinical and therapeutic implications. Leukemia 2008, 22:1095-1105.

12. Galasso M, Elena Sana M, Volinia S: Non-coding RNAs: a key to future personalized molecular therapy? Genome Med 2010, 2:12.

13. Calin GA, Liu CG, Ferracin M, Hyslop T, Spizzo R, Sevignani C, Fabbri M, Cimmino A, Lee EJ, Wojcik SE, Shimizu M, Tili E, Rossi S, Taccioli C, Pichiorri F, Liu X, Zupo S, Herlea V, Gramantieri L, Lanza G, Alder H, Rassenti L, Volinia S, Schmittgen TD, Kipps TJ, Negrini M, Croce CM: Ultraconserved regions encoding ncRNAs are altered in human leukemias and carcinomas. Cancer Cell 2007, 12:215-229.

14. Rossi S, Sevignani C, Nnadi SC, Siracusa LD, Calin GA: Cancer-associated genomic regions (CAGRs) and noncoding RNAs: bioinformatics and therapeutic implications. Mamm Genome 2008, 19:526-540.
15. Scaruffi P, Stigliani S, Moretti S, Coco S, De Vecchi C, Valdora F, Garaventa A, Bonassi S, Tonini GP: Transcribed-ultra conserved region expression is associated with outcome in high-risk neuroblastoma. BMC Cancer 2009, 9:441

16. Mestdagh $P$, Fredlund E, Pattyn F, Rihani A, Van Maerken T, Vermeulen J, Kumps C, Menten B, De Preter K, Schramm A, Schulte J, Noguera R, Schleiermacher G, Janoueix-Lerosey I, Laureys G, Powel R, Nittner D, Marine $J C$, Ringnér $M$, Speleman F, Vandesompele J: An integrative genomics screen uncovers ncRNA T-UCR functions in neuroblastoma tumours. Oncogene 2010, 29:3583-3592.

17. Yang R, Frank B, Hemminki K, Bartram CR, Wappenschmidt B, Sutter C, Kiechle M, Bugert P, Schmutzler RK, Arnold N, Weber BH, Niederacher D, Meind A, Burwinkel B: SNPs in ultraconserved elements and familial breast cancer risk. Carcinogenesis 2008, 29:351-355.

18. Volinia S, Calin GA, Liu CG, Ambs S, Cimmino A, Petrocca F, Visone R, Iorio M, Roldo C, Ferracin M, Prueitt RL, Yanaihara N, Lanza G, Scarpa A Vecchione A, Negrini M, Harris CC, Croce CM: A microRNA expression signature of human solid tumors defines cancer gene targets. Proc Natl Acad Sci U S A 2006, 103:2257-2261.

19. Bolstad BM, Irizarry RA, Astrand M, Speed TP: A comparison of normalization methods for high density oligonucleotide array data based on variance and bias. Bioinformatics 2003, 19:185-193.

20. Landgraf P, Rusu M, Sheridan R, Sewer A, lovino N, Aravin A, Pfeffer S, Rice A, Kamphorst AO, Landthaler M, Lin C, Socci ND, Hermida L, Fulci V, Chiaretti S, Foà R, Schliwka J, Fuchs U, Novosel A, Müller RU, Schermer B, Bissels U, Inman J, Phan Q, Chien M, Weir DB, Choksi R, De Vita G, Frezzetti $D$, Trompeter $\mathrm{Hl}$, et al: A mammalian microRNA expression atlas based on small RNA library sequencing. Cell 2007, 129:1401-1414.

21. Simon R, Lam A, Li MC, Ngan M, Menenzes S, Zhao Y: Analysis of gene expression data using BRB-ArrayTools. Cancer Inform 2007, 3:11-17. [http://linus.nci.nih.gov/BRB-ArrayTools.html]

22. Busch A, Richter AS, Backofen R: IntaRNA: efficient prediction of bacterial sRNA targets incorporating target site accessibility and seed regions. Bioinformatics 2008, 24:2849-2856.

23. Richter AS, Schleberger C, Backofen R, Steglich C: Seed-based INTARNA prediction combined with GFP-reporter system identifies mRNA targets of the small RNA Yfr1. Bioinformatics 2010, 26:1-5.

24. Gruber AR, Lorenz R, Bernhart SH, Neubock R, Hofacker IL: The Vienna RNA websuite. Nucleic Acids Res 2008, 36:W70-W74

25. Volinia S, Galasso M, Costinean S, Tagliavini L, Gamberoni G, Drusco A, Marchesini J, Mascellani N, Sana ME, Abu Jarour R, Desponts C, Teitell M, Baffa R, Aqeilan R, lorio MV, Taccioli C, Garzon R, Di Leva G, Fabbri M, Catozzi M, Previati M, Ambs S, Palumbo T, Garofalo M, Veronese A, Bottoni A, Gasparini P, Harris CC, Visone R, Pekarsky Y, et al: Reprogramming of miRNA networks in cancer and leukemia. Genome Res 2010, 20:589-599.

26. Calin GA, Ferracin M, Cimmino A, Di Leva G, Shimizu M, Wojcik SE, lorio MV, Visone R, Sever NI, Fabbri M, luliano R, Palumbo T, Pichiorri F, Roldo C, Garzon R, Sevignani C, Rassenti L, Alder H, Volinia S, Liu CG, Kipps TJ, Negrini M, Croce CM: A MicroRNA signature associated with prognosis and progression in chronic lymphocytic leukemia. N Engl J Med 2005, 353:1793-1801.

27. Visel A, Minovitsky S, Dubchak I, Pennacchio LA: VISTA Enhancer Browser-a database of tissue-specific human enhancers. Nucleic Acids Res 2007 35:D88-D92.

28. Ernst J, Kheradpour P, Mikkelsen TS, Shoresh N, Ward LD, Epstein CB, Zhang X, Wang L, Issner R, Coyne M, Ku M, Durham T, Kellis M, Bernstein BE: Mapping and analysis of chromatin state dynamics in nine human cell types. Nature 2011, 473:43-49.

29. Sigova AA, Mullen AC, Molinie B, Gupta S, Orlando DA, Guenther MG, Almada AE, Lin C, Sharp PA, Giallourakis CC, Young RA: Divergent transcription of long noncoding RNA/mRNA gene pairs in embryonic stem cells. Proc Natl Acad Sci U S A 2013, 110:2876-2881.

30. Magee JA, Piskounova E, Morrison SJ: Cancer stem cells: impact, heterogeneity, and uncertainty. Cancer Cell 2012, 21:283-296.

31. Watkins S, Sontheimer $\mathrm{H}$ : Unique biology of gliomas: challenges and opportunities. Trends Neurosci 2012, 35:546-556.

32. Zhang X, Sun S, Pu JK, Tsang AC, Lee D, Man VO, Lui WM, Wong ST, Leung GK: Long non-coding RNA expression profiles predict clinical phenotypes in glioma. Neurobiol Dis 2012, 48:1-8.

33. Gronych J, Pfister SM, Jones DT: Connect four with glioblastoma stem cell factors. Cell 2014, 157:525-527. 
34. Lujambio A, Portela A, Liz J, Melo SA, Rossi S, Spizzo R, Croce CM, Calin GA, Esteller M: CpG island hypermethylation-associated silencing of non-coding RNAs transcribed from ultraconserved regions in human cancer. Oncogene 2010, 29:6390-6401.

35. Hudson RS, Yi M, Volfovsky N, Prueitt RL, Esposito D, Volinia S, Liu CG, Schetter AJ, Van Roosbroeck K, Stephens RM, Calin GA, Croce CM, Ambs S: Transcription signatures encoded by ultraconserved genomic regions in human prostate cancer. Mol Cancer 2013, 12:13.

36. Lorenz R, Bernhart SH, Honer Zu Siederdissen C, Tafer H, Flamm C, Stadler PF, Hofacker IL: ViennaRNA Package 2.0. Algorithms for molecular biology. AMB 2011, 6:26.

37. Muckstein U, Tafer H, Hackermuller J, Bernhart SH, Stadler PF, Hofacker IL: Thermodynamics of RNA-RNA binding. Bioinformatics 2006, 22:1177-1182.

38. Chang TH, Huang HY, Hsu JB, Weng SL, Horng JT, Huang HD: An enhanced computational platform for investigating the roles of regulatory RNA and for identifying functional RNA motifs. BMC Bioinformatics 2013, 14:S4.

39. Bar M, Wyman SK, Fritz BR, Qi J, Garg KS, Parkin RK, Kroh EM, Bendoraite A, Mitchell PS, Nelson AM, Ruzzo WL, Ware C, Radich JP, Gentleman R, Ruohola-Baker $\mathrm{H}$, Tewari M: MicroRNA discovery and profiling in human embryonic stem cells by deep sequencing of small RNA libraries. Stem Cells 2008, 26:2496-2505.

40. Li Y, Mine T, loannides CG: Short GC-rich RNA similar to miR 1909 and 1915 folds in silico with the $5^{\prime}$-UTR and ORF of Notch and responders: potential for the elimination of cancer stem cells. Oncol Rep 2010, 24:1443-1453

41. Saito K, Inagaki K, Kamimoto T, Ito Y, Sugita T, Nakajo S, Hirasawa A, Iwamaru A, Ishikura T, Hanaoka H, Okubo K, Onozaki T, Zama T: MicroRNA-196a is a putative diagnostic biomarker and therapeutic target for laryngeal cancer. PloS One 2013, 8:e71480.

42. Li X, Lu Y, Chen Y, Lu W, Xie X: MicroRNA profile of paclitaxel-resistant serous ovarian carcinoma based on formalin-fixed paraffin-embedded samples. BMC Cancer 2013, 13:216.

doi:10.1186/s13073-014-0076-4

Cite this article as: Galasso et al:: A large scale expression study associates uc.283-plus IncRNA with pluripotent stem cells and human glioma. Genome Medicine 2014 6:76.

\section{Submit your next manuscript to BioMed Central and take full advantage of:}

- Convenient online submission

- Thorough peer review

- No space constraints or color figure charges

- Immediate publication on acceptance

- Inclusion in PubMed, CAS, Scopus and Google Scholar

- Research which is freely available for redistribution 